\title{
1 Exceptional Late Devonian arthropods document the origin of decapod
}

$10 \quad{ }^{3}$ Department of Zoology, Faculty of Science, Charles University, Viničná 7, 12800, Prague 2.

$11{ }^{4}$ University of Silesia in Katowice, Faculty of Natural Sciences, Institute of Earth Sciences,

12 Będzińska 60, 41-200 Sosnowiec, Poland.

$13{ }^{5}$ Department of Geological Sciences, Faculty of Sciences, Masaryk University, Kotlářská 2, Brno

14602 00, Czech Republic.

15 SSlavkovského 864/9, 62700, Brno, Czech Republic.

$16{ }^{7}$ Královopolská 34, 616, Brno, Czech Republic.

$17{ }^{8}$ Muséum national d'Histoire naturelle, Sorbonne Université, CNRS UMR 7207, CR2P, Centre de

18 Recherche en Paléontologie - Paris, 8 rue Buffon, 75005, Paris, France

$19{ }^{9}$ Museum of Comparative Zoology and Department of Organismic and Evolutionary Biology,

20 Harvard University, 26 Oxford Street, Cambridge, MA, 02138, USA.

$21{ }^{10}$ Department of Earth and Planetary Sciences, Yale University, New Haven, CT 06511, USA.

$22{ }^{11}$ Smithsonian Tropical Research Institute, Balboa-Ancón 0843-03092, Panamá, Panamá.

$24 *$ e-mail: pierre.gueriau@hotmail.fr

27 ORCIDs

28 PG, 0000-0002-7529-3456; MZ, 0000-0001-5136-5286; SC, 0000-0003-2343-6897;

29 JL, 0000-0002-4391-5951 
Abstract

31 With over 15,000 extant species, Decapoda-or ten-legged crustaceans such as crabs, shrimp,

32 lobsters, and relatives - are among the most speciose and economically important group of

33 crustaceans. Despite of their diversity, anatomical disparity, and remarkable fossil record

34 extending back to the Late Paleozoic, the origins of Decapoda and their phylogenetic

35 relationships with eumalacostracans remains elusive and inconclusive. Molecular dating

36 suggests that decapods originated in the Late Ordovician ( $\sim 50 \mathrm{Mya}$ ), but no reliable fossil

37 crown groups are found until the Late Devonian. Moreover, there is no consensus on which

38 lineages belong to stem groups, obscuring our understanding of the roots of the ten-legged

39 decapod body plans as a whole, and how they relate to other non-decapod crustaceans. We

40 present new, exceptional fossils from the Late Devonian of Czech Republic and Poland that

41 belong to +Angustidontida, an odd shrimp-looking crustacean with a combination of anatomical

42 features unlike those of any crown eumalacostracan known-extinct or extant. Our

43 phylogenetic analyses, including representatives of all major lineages of crown eumalacostracans plus †Angustidontida, identify angustidontids as the only known stem-group decapod, and give hints about the transformation series, polarity of change, and evolutionary pathways leading to the modern decapod body plans seen today.

Keywords: Angustidontida, Konservat Lagerstätte, origins, Paleozoic, phylogeny, evolution

\section{Introduction}

Among crustaceans, the representatives of the order Decapoda are easily recognizable due to

53 their distinctive body forms. They have a carapace that is fused to the underlying thoracic segments, an abdomen (pleon) constituted by six segments or pleonites, and most lineages

55 other than crabs have a telson and uropods that often form a tailfan. Moreover, crown-group decapods have eight pairs of thoracic appendages or thoracopods, from which the first three

57 pairs are modified into maxillipeds for feeding, while the remaining five pairs are developed

58 into true thoracic legs (pereopods), hence the name of the order (Decapoda = ten-footed 
crustaceans) (e.g. [1]). Despite of such a distinctive body arrangement, the deep relationships among decapods have long been conflicting and unresolved. Recent phylogenomic analyses with assembled sequence data from 94 species (including 11 of the 12 major lineages) recovered a robust extant decapod tree of life [2]. Unfortunately, the origin of Decapoda remains obscure as i) there is no consensus on the sister group to crown-group Decapoda, and ii) no stem-group decapod forms have been confirmed from reliable Paleozoic (Late DevonianCarboniferous) fossils [3], with the latter being too derived or insufficiently preserved to be informative about the origins of the total-group Decapoda [1,3,4]. Furthermore, molecular divergence times suggest that crown decapods diverged in the Late Ordovician, leaving a gap of nearly 70 million years between their estimated split and their earliest confirmed fossils, and implying a significant cryptic Paleozoic history [2].

Among the few known middle Paleozoic eumalacostracan crustaceans, the iconic shrimp-looking †Angustidontida from Late Devonian and Early Carboniferous of North America and Europe have been envisioned as closely related to decapods $[1,2,4,5]$. Unlike crown decapods, †Angustidontida bears one or two pairs of elongated comb-like maxillipeds (figure 1a; one pair in †Angustidontus Cooper, 1936, two pairs in †Schramidontus Gueriau, Charbonnier \& Clément, 2014 [4]). Isolated remains of such comb-like maxilliped were described as either actinopterygian fish jaws, eurypterid raptorial appendages, or crustacean appendages $[1,5]$, until more complete and articulated material confirmed their crustacean affinities. †Angustidontida is morphologically similar to Decapoda [4], but differs from it in the number of maxillipeds and the size and connection of the pleonal segments (uniform in angustidontids; variable in most decapods, with an expanded second pleonal pleuron and an enlarged third pleonal somite). In particular, angustidontids exhibit remarkable similarity with †Palaeopalaemon newberryi Whitfield, 1880, another fossil crustacean from the Late Devonian recognized undoubtedly as a crown decapod $[6,7]$, yet $+P$. newberryi is distinct from angustidontids [7]. Gueriau et al. [4] postulated that angustidontids were early decapods that filled the gap between krill or Euphausiacea (no maxillipeds) and Decapoda (three pairs of maxillipeds), and that they were closer to Decapoda than to the extant Amphionides reynaudii 
88 trait placed Amphionides as the sister taxon to Decapoda, and it was so unique that merited its own order Amphionidacea [8]. The single pair of maxillipeds of $A$. reynaudii told a beautiful

90 story about the possible origins of Decapoda, and filled the gap between Euphausiacea and

91 Decapoda, but it took an unexpected turn when molecular phylogenetics identified

92 Amphionidacea as the larval form of a caridean decapod shrimp [9]. As a consequence,

93 TAngustidontida stood as the only remaining sister group candidate to Decapoda, or at least

94 the only extinct lineage recognizable between euphausiaceans and decapods [1]. However, the

95 angustidontid material described so far does not exhibit any character autapomorphic of

96 Decapoda [4], for which new material and a revision in a more explicit phylogenetic framework 97 is still lacking [2].

98 Here, we describe new anatomical features of †Angustidontida based on new,

99 exceptional fossils from the Late Devonian of Czech Republic and Poland, showing in

100 exceptional detail pleonal and caudal features that allow us to explore their phylogenetic

101 position within Malacostraca, and its systematic implications for understanding the origins of

102 crown decapod crustaceans.

\section{2. Materials and methods}

106 (a) Material

107 The fossil specimens investigated herein come from the Hády quarry (lower Fammenian, Czech

108 Republic; see next section for geological settings) and the Kowala quarry (lower Fammenian,

109 Holy Cross Mountains, Poland; see [10] for geological settings), and are housed at the Czech

110 Geological Survey, Prague, and the Institute of Earth Sciences, University of Silesia, Sosnowiec,

111 respectively. Fossils from the Hády quarry presented herein (figure $1 b-e$ and electronic

112 supplementary material, figure S1) have never been published or mentioned before; the

113 specimen from the Kowala quarry (figure $1 f-h$ ) have been mentioned, but not figured in [10].

114 They were studied under a binocular microscope, both dry and covered in water with a low

115 angle light to better reveal relief, and photographed with a SLR camera coupled with macro lens

116 equipped with polarizing filters. Interpretative line drawings were produced on the 
117 photographs while observing the specimens with different light angles under the binocular

118 microscope. Drawings and figures were made using Adobe Illustrator.

(b) Geological settings and stratigraphy of the Hády quarry, Czech Republic

121 The new angustidontid material from Czech Republic comes from section H33 of the Hády

122 quarry (part Městký lom), northeastern outskirts of Brno, Czech Republic. The Hády quarry

123 exposes a southernmost outcrop of the Moravian Karst Paleozoic, belonging to the Variscan

124 Brunovistulian Unit. Devonian and Carboniferous sedimentary rocks of the Brunovistulian Unit

125 were deposited at a southern margin of Laurussia $[11,12,13,14]$.

126 In the Hády quarry, Late Frasnian pure massive limestones of the Macocha Formation

127 are overlain by the latest Frasnian to late Famennian nodular to well bedded limestones of the

128 Líšeň Formation (electronic supplementary material, figure S1). A drowning of the Frasnian

129 outer ramp and transition to an Famennian hemipelagic slope environment with turbiditic

130 influence is recorded in the studied section $[15,16,17])$. Angustidontid-bearing bed is one of the

131 calcareous shale intercalations, which alternate with platy calcilutites and occasional banks of

132 medium-grained calcirudites (electronic supplementary material, figure S1). The calcareous

133 shales represent "background" hemipelagic facies deposited in relatively low-energy slope

134 environment, well below storm-wave base. The platy limestones were interpreted as

135 calciturbidites (e.g. $[16,18,19])$. Limestone sample just below the angustidontid-bearing shale

136 yielded 110 conodonts, which are typical for the lower Famennian Palmatolepis minuta minuta

137 to Palmatolepis crepida conodont zones interval (sensu [20]), involving Pa. triangularis, Pa.

138 minuta minuta, Pa. delicatula delicatula and Icriodus alternatus.

$140 \quad$ (c) Phylogenetic analysis.

141 We investigated the phylogenetic position of †Angustidontida using a modified morphological

142 dataset for malacostracan crustaceans after [8] (characters 1-93). Following [21], we added

143 four additional characters related to the morphology of the basipods and uropods (characters

144 94-97). The operational taxonomic unit (OTU) 'Amphionidacea', included in the analyses of [8],

145 was culled from our analysis as it has been demonstrated that amphionidaceans are the larvae 
146 of a decapod shrimp rather than a distinct malacostracan order $[1,9]$. The final data matrix,

147 containing 19 OTUs ( 3 in outgroup, 16 in ingroup) and 97 adult morphological characters, was

148 built in Mesquite 3.51 [22]. Undetermined or not preserved characters were scored as '?', and

149 inapplicable characters as '-'. Multiple character states present in a given OTU were scored as

150 polymorphisms.

151 We analyzed the dataset using Bayesian inference (BI) as implemented in MrBayes

152 v.3.2.5 [23]. The dataset was analyzed under the traditional Mk model [24] with an

153 ascertainment bias correction to account for scoring only variable morphological characters,

154 and gamma distributed rate variation. Each analysis was performed with two independent runs

155 of $3 \times 10^{7}$ generations each. We used the default settings of four chains per independent run.

156 The relative burn-in fraction was set to $25 \%$, and the chains were sampled every 200

157 generations. We used Tracer v. 1.7.1 [25] to determine whether the runs reached stationary

158 phase and to ensure that the effective sample size for each parameter was greater than 200.

159 Results of the Bayesian runs were summarized as a majority-rule consensus tree of the post-

160 burnin sample (figure 2).

161 We also conducted maximum parsimony (MP) phylogenetic analyses in TNT v.1.5 [26].

162 The data was analyzed under implicit enumeration for equally weighted maximum parsimony

163 (EWMP) (figure S2a), and different implied weights $(K=3,6,12)$ as additional tests of placement

164 of †Angustidontida (electronic supplementary material, figure $S 2 b-d$ ). Bootstrap and jackknife

165 values were calculated after 10,000 replications each using default settings. Bremer support

166 values for the EWMP implicit enumeration were calculated under tree bisection reconnection,

167 and retained trees suboptimal by 30 steps. All characters were unordered.

\section{Results and discussion}

171 New material assigned to †Angustidontus aff. moravicus Chlupáč, 1978 [11] collected from

172 Czech Republic (figure $1 b-e$ and electronic supplementary material, figure S1), and

173 tAngustidontus aff. seriatus Cooper, 1936 from Poland (figure $1 f-h$ ) reveals fine details of the

174 anatomy of their tailfan previously unknown, which in turn allow for a detailed taxonomic and 
175 phylogenetic comparison with other malacostracans. The angustidontid tailfan consists of a

176 triangular telson flanked by two pairs of leaf-shaped uropods (figure $1 b-d, g, h$; see also [4,5]).

177 The uropodal exopod bears a carina, and prolongs latero-distally in a non-articulated, spiky

178 outgrowth (figure $1 d, h$ arrowheads). The lateral, distal, and median margins of the endopod

179 and exopod (up to the spiky outgrowth for the latter) are surrounded by plumose setae of

180 different length, longest distally and shortest proximo-medially and latero-distally (figure $1 g, h$ ).

181 The basipod is sub-conical and possesses a latero-distal, tipped prolongation (figure $1 e, h$

182 arrows; see also [5]). According to Kutschera et al. [21]'s work on the phylogenetic signal

183 conveyed by malacostracan basipods and uropods morphology, such combination of characters

184 is unique to Decapoda. It is worth noting that, as described by Rolfe and Dzik [5], the uropodal

185 exopod is not divided into two portions by a medio-lateral suture or diaeresis, a feature also

186 absent in Euphausiacea and Dendrobranchiata (though some fossils assigned to the group do

187 possess one $[27,28,29])$ but found in Caridea [21]. The presence or absence of a longitudinal

188 median keel on the basipod, specific to Decapoda [21], is impossible to determine on our

189 flattened fossil material. Aside this, the anatomy of the angustidontid tailfan is virtually

190 identical to that of decapods (figure 1i), adding support to an alliance between these groups.

Bayesian inference and maximum parsimony phylogenetic analyses recover

192 TAngustidontida as the sister group to the crown-group Decapoda (figure 2, and electronic

193 supplementary material, figure S2). Besides filling the gap between Euphausiacea and

194 Decapoda, an affiliation of angustidontids as the closest known sister taxon to crown group

195 Decapoda, i.e. as part of total-group Decapoda, has important implications for reconciling

196 molecular divergence dates for decapods (Late Ordovician [2]) and their earliest known fossil

197 record (Late Devonian [1,3,4,6,7]). Our findings identify angustidontids as the only stem-group

198 decapod known to date, and suggest that their apparently cryptic Paleozoic history [2] might be

199 an artifact of the overlooked disparate stem-decapod body plans, compared to crown-group

200 forms. Our results indicate that the origin of decapod-like eucaridans lies within more than ten-

201 footed crustaceans, and gives hints about the transformation series, polarity of change, and

202 evolutionary pathways leading to the characteristic decapod body arrangement and

203 thoracopod configuration seen across the main crown groups as recognized today. 
(a)
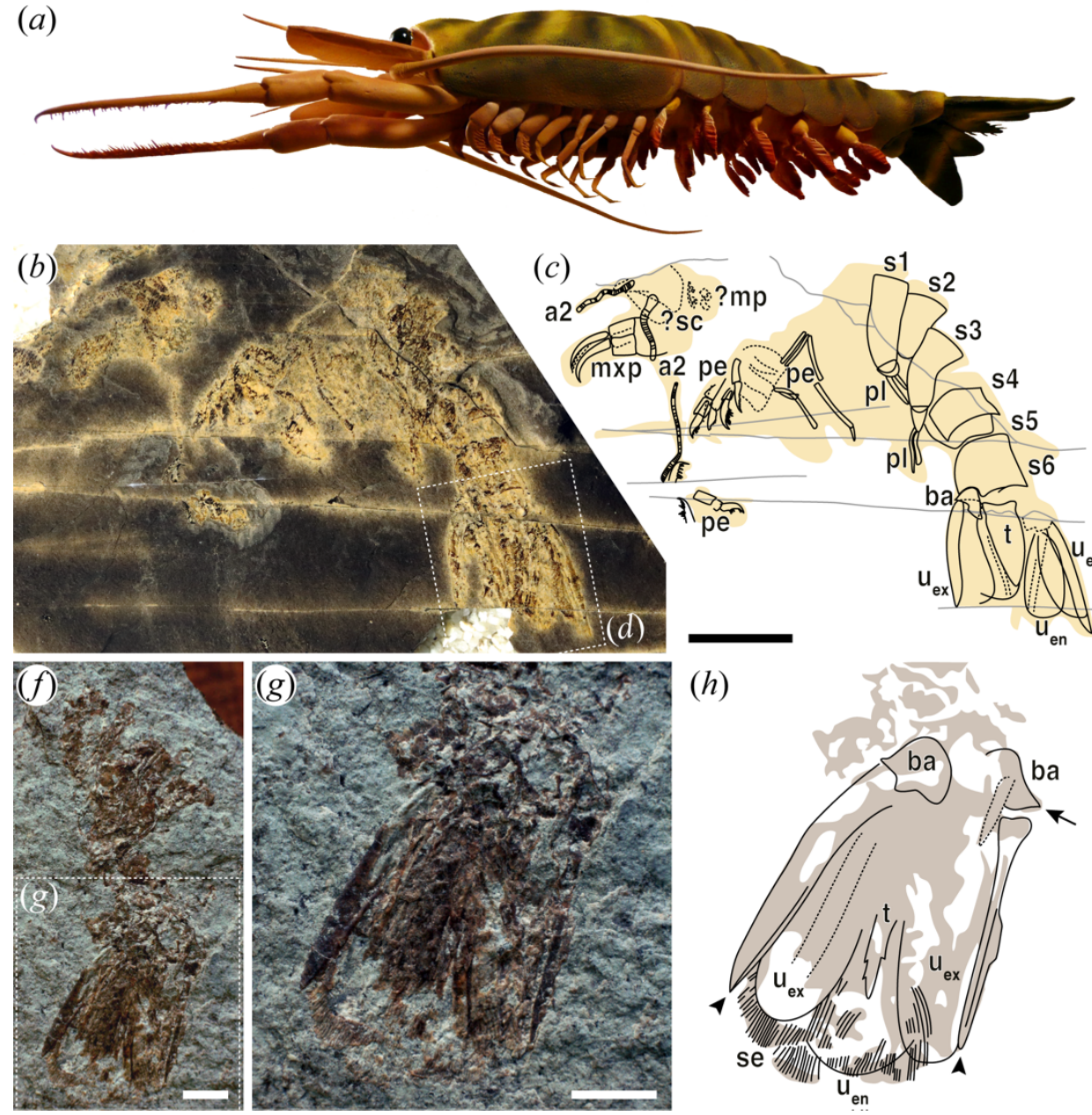

$(h)$

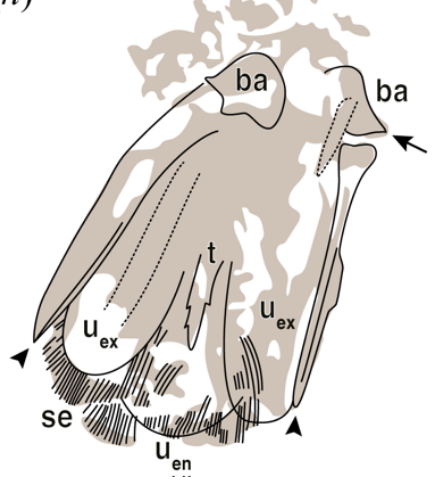

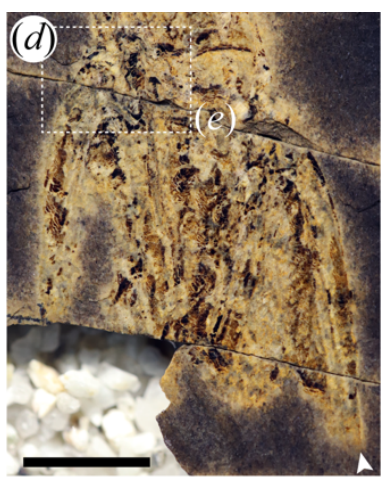

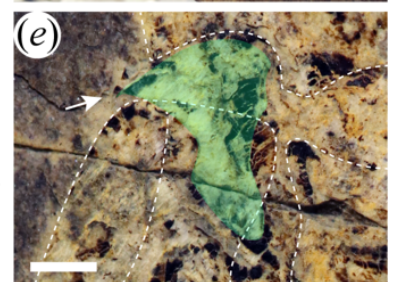

(i)

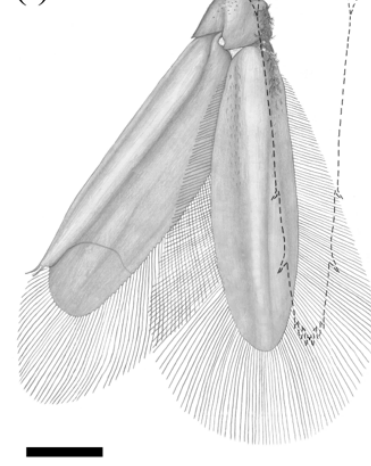

Figure 1. Angustidontid tailfan anatomy. (a) Reconstruction of + Angustidontus in ventro-lateral view; SHAPE-PLAST thermoplastic model by T.V. $(b-e)+$ Angustidontus aff. moravicus, H33/1A, complete specimen (likely an exuvia) in dorso-lateral view from the Hády quarry (lower Fammenian, Czech Republic). (b) Photo of specimen covered in water. (c) Interpretative line drawing. (d) Close-up of the tailfan, from the box area in $b$. (e) Close-up of the basipod (highlighted in green), from the box area in $d$. $(f-h)$ †Angustidontus aff. seriatus, GIUS 4-3622/kor112, articulated pleon in dorso-lateral view from the Kowala quarry (lower Fammenian, Holy Cross Mountains, Poland). (f) Photo dry. (g) Close-up of the tailfain, from the box area in $f$. ( $h$ ) Interpretative line drawing. (i) Pencil drawing of the uropods of the extant shrimp Crangon crangon Linnaeus, 1758. Illustration by Dr. Verena Kutschera. Abbreviations: a2, antenna; ba, basipod; ?mp, ?mouth parts; mxp, maxillipeds; pe, pereopods; pl, pleopods; s1-s6; pleonal somites 1 to 6 ; se, setae; ?sc, ?scaphocerites; t, telson; $u_{e n}$, uropodal endopod; $u_{e x}$, uropodal exopod.

217 Arrowheads and arrows point out the latero-distal spiky outgrowth of $u_{e x}$ carina, and the latero-distal

218 tipped prolongation of the basipod, respectively. Scale bars, $1 \mathrm{~cm}$ in $b$ and $c, 5 \mathrm{~mm}$ in $d, 2 \mathrm{~mm}$ in $f-h$, and $2191 \mathrm{~mm}$ in $e$ and $i$. 


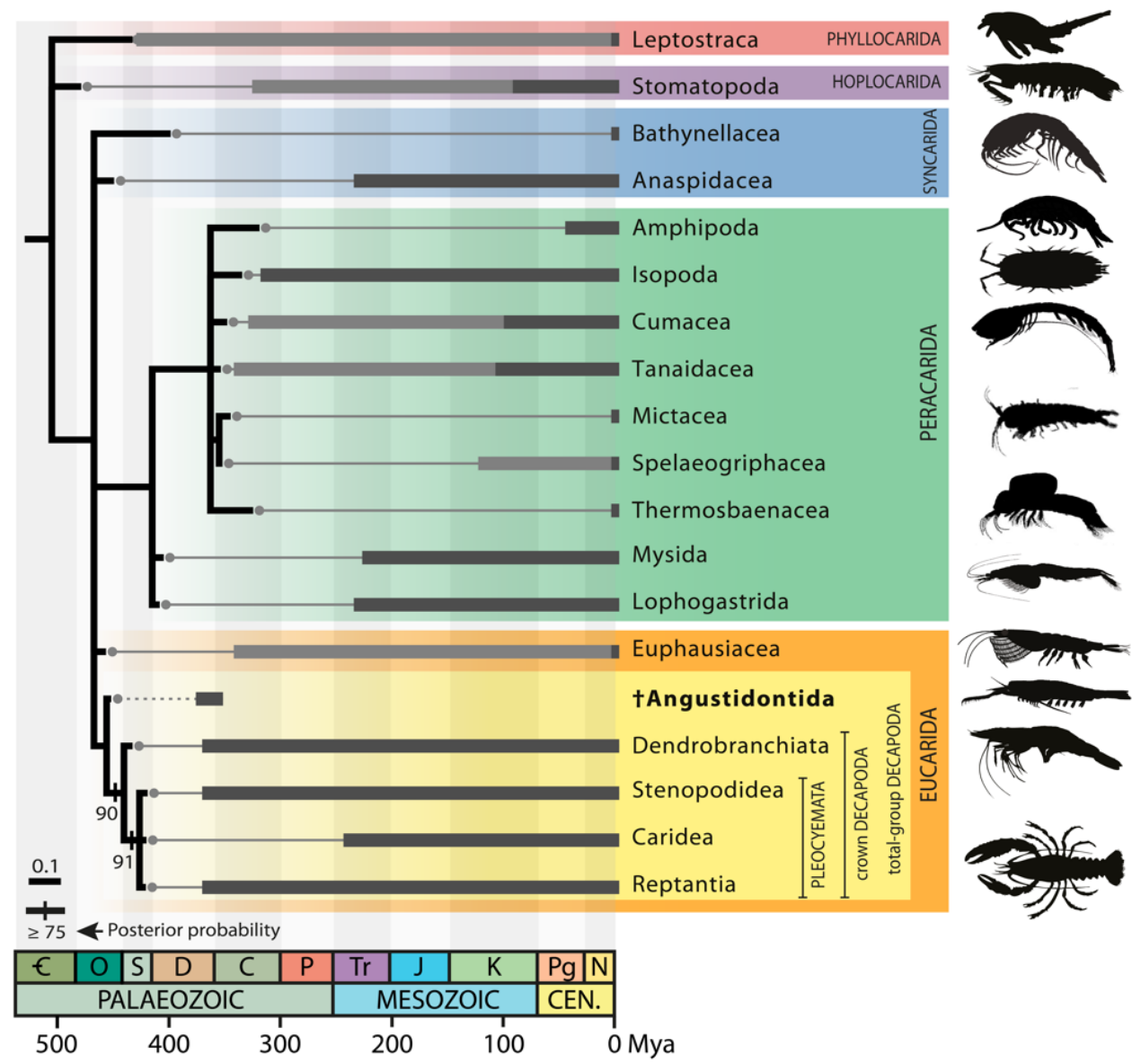

Figure 2. Phylogenetic position of angustidontids within malacostracan crustaceans. Bayesian majorityrule consensus topology of the post-burnin sample of trees, plotted on stratigraphy. The obtained tree (black line) was scaled to accommodate a Late Ordovician divergence date for Decapoda [2] and the stratigraphic ranges of terminal taxa (light and dark grey thick lines for stem- and crown-groups, respectively; see electronic supplementary material, table $\mathrm{S} 1$, for ages justification) here constrained by the first occurrence of stem Leptostraca. Posterior probability support values indicated above branches. Branches with posterior probability support $<75 \%$ are collapsed.

\section{References}

234 1. Hegna TA, Luque J, Wolfe JM. 2020 The fossil record of the Pancrustacea. In Poore G, Thiel M (eds.) The Natural History of the Crustacea: Evolution and Biogeography of the Crustacea, Volume 8, 21-52. Oxford University Press. (ISBN: 9780190637842) 
resources for comparative studies of decapod crustaceans. Proceedings of the Royal Society

B 286, 20190079. (doi:10.1098/rspb.2019.0079)

3. Schram FR. 2009 On the origin of Decapoda. In Martin JW, Crandall KA, Felder DL (eds.) Decapod Crustacean Phylogenetics, 3-14. CRC Press, Boca Raton, FL. (ISBN: 978-1-42009258-5)

4. Gueriau P, Charbonnier S, Clément G. 2014 Angustidontid crustaceans from the Late Devonian of Strud (Namur Province, Belgium): insights into the origin of Decapoda. Neues Jahrbuch für Geologie und Paläontologie 273, 327-337. (doi:10.1127/0077$7749 / 2014 / 0434)$

5. Rolfe WDI, Dzik J. 2006 Angustidontus, a Late Devonian pelagic predatory crustacean. Earth and Environmental Science Transactions of The Royal Society of Edinburgh 97, 75-96. (doi:10.1017/S0263593300001413)

6. Schram FR, Feldmann RM, Copeland MJ. 1978 The Late Devonian Palaeopalaemonidae and the earliest decapod crustaceans. Journal of Paleontology 52, 1375-1387.

8. Richter S, Scholtz G. 2001 Phylogenetic analysis of the Malacostraca (Crustacea). J. Zool.

Syst. Evol. Research 39, 113-136. (doi:10.1046/j.1439-0469.2001.00164.x)

9. De Grave S, Cha, T-Y, Chu KH, Yang C-H, Landeira JM. 2015 Phylogenetics reveals the crustacean order Amphionidacea to be larval shrimps (Decapoda: Caridea). Scientific Reports 5, 17464. (doi:10.1038/srep17464)

10. Zatoń M, Filipiak P, Rakociński M, Krawczyński W. 2014 Kowala Lagerstätte: Late Devonian arthropods and non-biomineralized algae from Poland. Lethaia 47, 352-364. (doi:10.1111/let.12062)

11. Chlupáč I. 1978. The problematical arthropods of the Family Angustidontidae in the Upper Devonian of Moravia, Czechoslovakia. Časopis pro Mineralogii a Geologii 23, 233-241. 
12. Finger F, von Quadt A, Pin C, Steyrer HP. 1998 The ophiolite chain along the western Moravo-Silesian plate margin; a trace of the Rheic Suture? Acta Universitatis Carolinae, Geologica 42, 244-245.

13. Hladil J, Melichar R, Otava J, Galle A, Krs M, Man O, Pruner P, Cejchan P, Orel P. 1999 The Devonian in the Easternmost Variscides, Moravia; a holistic analysis directed towards comprehension of the original context. Abhandlungen der Geologischen Bundesanstalt 54, 27-47.

14. Kalvoda J, Bábek O, Fatka O, Leichmann J, Melichar R, Špaček P. 2008 Brunovistulian terrane (Bohemian Massif, Central Europe) from late Proterozoic to late Paleozoic: a review. International Journal of Earth Sciences 97, 497-517. (doi:10.1007/s00531-0070183-1)

15. Hladil J, Krejčí Z, Kalvoda J, Ginter M, Galle A, Berousek P. 1991 Carbonate ramp environment of Kellwasser time-interval; Lesni lom, Moravia, Czechoslovakia. Bulletin de la Société Belge de Géologie 100, 57-119.

16. Bábek O, Přikryl T, Hladil J. 2007 Progressive drowning of carbonate platform in the

17. Weiner T, Kalvoda J, Kumpan T, Schindler E, Šimíček D. 2017 An integrated stratigraphy of

18. Kalvoda J, Bábek O, Malovaná A. 1999 Sedimentary and Biofacies Record in Calciturbidites at the Devonian-Carboniferous Boundary in Moravia (Moravian Silezian Zone, Middle

19. Kumpan T, Bábek O, Kalvoda J, Frýda J, Matys Grygar T. 2014. A high-resolution, multiproxy stratigraphic analysis of the Devonian-Carboniferous boundary sections in the Moravian Karst (Czech Republic) and a correlation with the Carnic Alps (Austria). Geological Magazine 151, 201-215. (doi:10.1017/S0016756812001057) 
20. Spalleta C, Perri MC, Over DJ, Corradini C. 2017 Famennian (Upper Devonian) conodont zonation: revised global standard. Bulletin of Geosciences 92, 31-57. (doi:10.3140/bull.geosci.1623)

21. Kutschera V, Mass A, Waloszek D. 2012 Uropods of Eumalacostraca (Crustacea s.I.: Malacostraca) and their phylogenetic significance. Arthropod Systematics and Phylogeny 70, 181-206.

22. Maddison WP, Maddison DR. 2018 Mesquite: a modular system for evolutionary analysis. Version $3.51 \mathrm{http}: / /$ mesquiteproject.org

23. Ronquist F, Teslenko M, van der Mark P, Ayres DL, Darling A, Höhna S, Larget B, Liu L,

24. Lewis PO. 2011 A Likelihood Approach to Estimating Phylogeny from Discrete Morphological Character Data. Systematic Biology 50, 913-925. (doi:10.1080/106351501753462876) Suchard MA, Huelsenbeck JP. 2012 MrBayes 3.2: efficient Bayesian phylogenetic inference and model choice across a large model space. Systematic Biology 61, 539-542.

26. Goloboff PA, Farris JS, Nixon KC. 2008 TNT, a free program for phylogenetic analysis.

25. Rambaut A, Drummond AJ, Xie D, Baele G, Suchard MA. 2018 Posterior summarisation in Cladistics 24, 774-786. (doi:10.1111/j.1096-0031.2008.00217.x)

27. Glaessner MF. 1969 Decapoda. In Moore RC (ed.) Treatise on Invertebrate Paleontology, Part R, Arthropoda 4, 399-533. Geological Society of America and University of Kansas.

28. Audo D, Charbonnier S. 2013 Late Cretaceous crest-bearing shrimps from the Sahel Alma Lagerstätte of Lebanon. Acta Palaeontologica Polonica 58, 335-349.

29. Charbonnier S, Audo D, Garassino A, Hyžný M. 2017 Fossil Crustacea of Lebanon. Mémoires du Muséum national d'Histoire naturelle 210, 252 p. (ISBN: 978-2-85653-785-5) 


\section{Additional information}

326 Data accessibility. Requests for materials should be addressed to Petr Budil (petr.budil@geology.cz) or

327 M.Z. (mzaton@wnoz.us.edu.pl) for the Hády quarry and the Kowala quarry, respectively. The

328 phylogenetic data matrix is available in Morphobank http://morphobank.org/permalink/?P3739.

329 Additional data are available as electronic supplementary material.

331 Authors' contributions. P.G. and S.R. conceived the project. S.R., K.B., T.K., T.V. and P.V. collected the 332 material from Czech Republic and composed the geological settings and Figure S1A. M.Z. collected and 333 provided photographs of the specimen from Poland. P.G., S.C. and J.L. defined the phylogenetic

334 characters and coded the matrix. J.L. conducted the phylogenetic analyses. P.G., S.R. and J.L. discussed 335 the results and P.G. prepared the manuscript with input from all other authors.

337 Competing interests. The authors declare no competing interests.

339 Funding. Part of this study was supported by the research project 19-17435S of the Czech Science 340 Foundation (GAČR). K.B. was supported by the National Science Center grant PRELUDIUM

341 (2015/19/N/ST10/01527). J.L. thanks the Natural Science and Engineering Research Council of Canada 342 Postdoctoral Fellowship (NSERC PDF), the Yale Institute for Biospheric Studies (YIBS), and the National 343 Science Foundation Grant DEB \#1856679 (USA).

345 Acknowledgements. We thank Dr. Verena Kutschera for the pencil drawing of the uropods of Crangon 346 crangon presented in figure $1 i$ and Dr. Frederick R. Schram for comments and suggestions about the 347 phylogenetic analysis at an early stage of this research. 